\title{
Las minas del Soldado y las Morras del Cuzna de Villanueva del Duque
}

Juan Andrés Molinero Merchán | IES Los Pedroches (Pozoblanco)

URL de la contribución <www.iaph.es/revistaph/index.php/revistaph/article/view/3493>

\section{RESUMEN}

El patrimonio industrial y minero de los Pedroches constituye un elemento fundamental en la reconstrucción del pasado más remoto y reciente (siglos XIX y XX) de la comarca. En los últimos años se está procediendo a la reconstrucción material y espiritual de este legado, así como la comprensión de la contextualidad en sus elementos esenciales; también el aprovechamiento de esos vestigios desde nuevas perspectivas económicas y culturales. Las minas del Soldado y las morras de Villanueva del Duque y Alcaracejos representan un ejemplo paradigmático de arqueología minera e industrial poseedora de un rico haber, que actualmente debe entenderse ampliamente: con una mirada integral del entorno territorial, la comprensión de los fundamentos geológicos existentes y los valores paisajísticos dominantes (la dehesa). Sobre todo la conservación de un legado que nos ha dejado la historia y nos permite conocer, aunque sea por una estrecha ventana, una perspectiva económica de la comarca que fue fundamental. Tomar conciencia de ello no debe ser simplemente una gentileza cultural, sino una necesidad inminente para comprender nuestra tierra y a nosotros mismos. Todo ello desde una perspectiva de utilización racional, al tenor de una explotación económica (turística) que necesariamente debe estar vinculada a la naturaleza y sostenibilidad del medio rural.

\footnotetext{
Palabras clave

Alcaracejos (Córdoba) | Andalucía | Castillo de Cuzna | Castillos | Córdoba (Provincia) | Fortificaciones | Patrimonio Conjunto minero El Soldado | Patrimonio industrial | Valle de los Pedroches (Córdoba) | Villanueva del Duque (Córdoba) |
} 


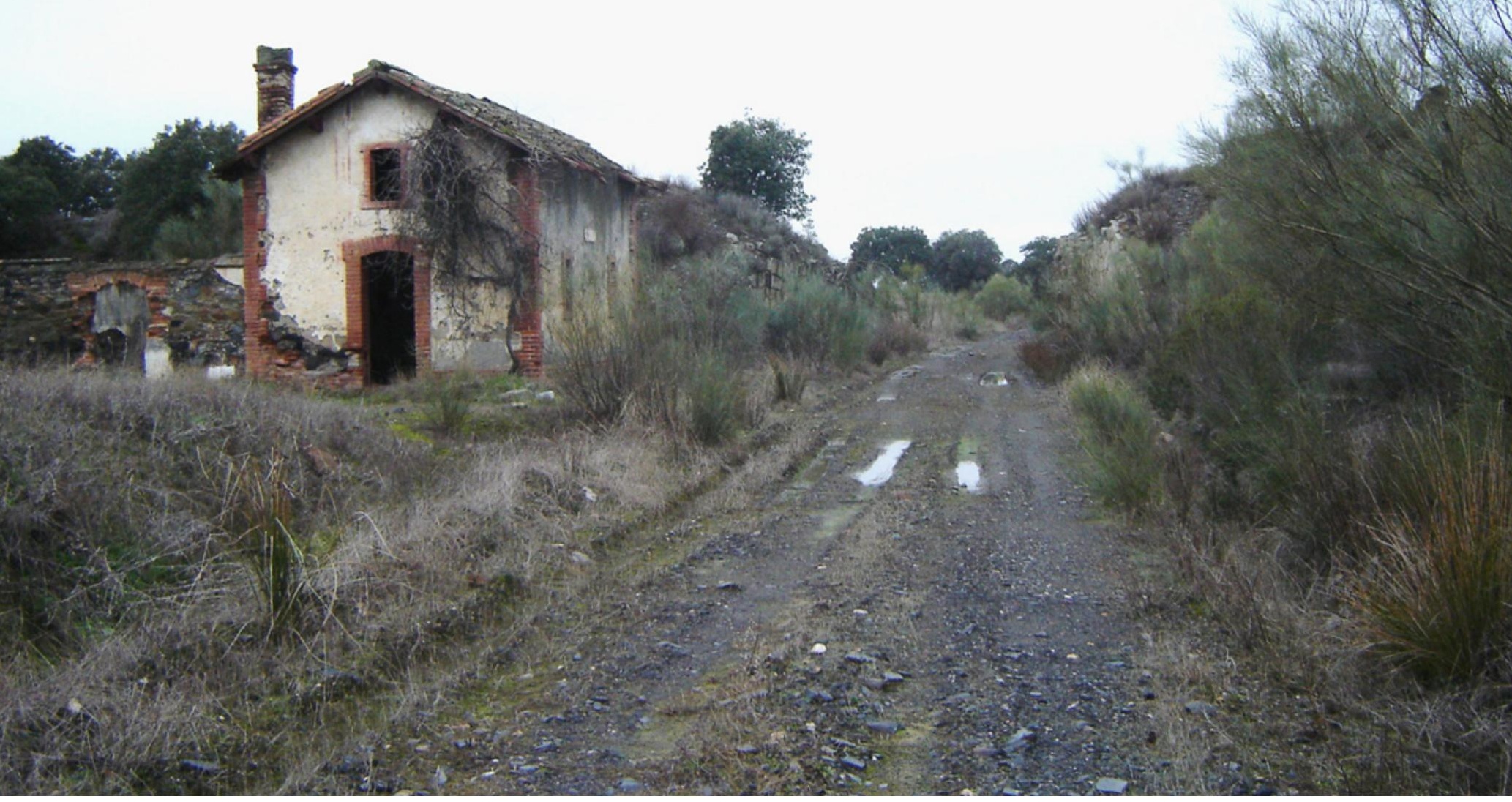

Vía verde sobre antiguo trazado del ferrocarril | foto Juan Andrés Molinero Merchán (de todas las imágenes del artículo) 
La comarca de los Pedroches es una tierra marcada en el pasado por la metalurgia. Geográficamente está muy definida por unidades exteriores que le confieren la apariencia de valle, sin serlo propiamente (VALLE, 1985), así como por una constitución geológica no carente de singularidad, que fueron determinantes para la explotación minera tradicional. Hoy día simplemente prevalece este legado minero e industrial en términos arqueológicos y museísticos, dormitando el sueño de la eternidad, con el prurito de revitalización turística y cultural. Veamos lo esencial. Entre los elementos definitorios de la configuración geológica se encuentra la presencia de un basamento granítico central, denominado Batolito de los Pedroches (CABANAS, 1968), con orientación NO-SE, bordeado de estructuras metamórficas (pizarras). Los yacimientos filonianos existentes son el resultado del flujo de los elementos metálicos residuales de la masa granítica cristalizada (JIMÉNEZ, 2005), que escapa a través de las fisuras precipitando en sus paredes las menas metálicas: acreditándose la presencia de cobre, pequeños filones de wolframio y estaño; asimismo, en el ámbito del metamorfismo, en la superficie de contacto con el granito aparecerán bismuto, cobalto y níquel, pero en zonas más alejadas se encuentran plomo, zinc y plata, que constituyen los filones más ricos de la metalurgia histórica y contemporánea (HERNANDO, 1989).

Con estos fundamentos geológicos se explica la historia minera de la comarca. Los primeros asentamientos fueron dispersos en el tiempo y en el espacio (Paleolítico, Neolítico...), con la ocupación completa del territorio a comienzos del Calcolítico y Edad de los Metales (MURILLO, 1987), así como la etapa subsiguiente prerromana (iberos y celtas), que validan el desarrollo de actividades agrarias y metalúrgicas (museo Prasa Torrecampo). La civilización romana dejó impregnada su huella de forma contundente (GARCíA ROMERO, 2002), sobre todo con restos metalúrgicos, a pesar de la precariedad del afloramiento de los legados históricos descollantes o ausencia de referencias literarias de nuestra comarca (MERINO, 2000): pues aún no han salido a flote los grandes conjuntos, como la antigua Solia, de la que desconocemos con certeza su situación, ubicándola los especialistas en las proximidades de la ermita de las Cruces del Guijo, cerro de Majadaiglesia (STYLOW, 1985). Dicho asentamiento formaba parte de la región de la Beturia habitada por los túrdulos (CORZO; JIMÉNEZ, 1980), en el convento jurídico de Cordubensis (uno de los cuatro que constituían la Bética).

Asimismo se asienta en esta demarcación territorial en época romana la población de Baedro (municipio de derecho latino), como atestiguan los vestigios arqueológicos funerarios; su emplazamiento debía estar en el ámbito occidental de la región, en el contexto geográfico de Hinojosa, Belalcázar y el Viso, aproximadamente. Entre ambas las poblaciones de Solia (al este) y Baedro (al oeste) discurría la calzada romana de Córduba-Sisapo, en una secuencia análoga a la carretera N-502 de nuestros días. La ocupación del 


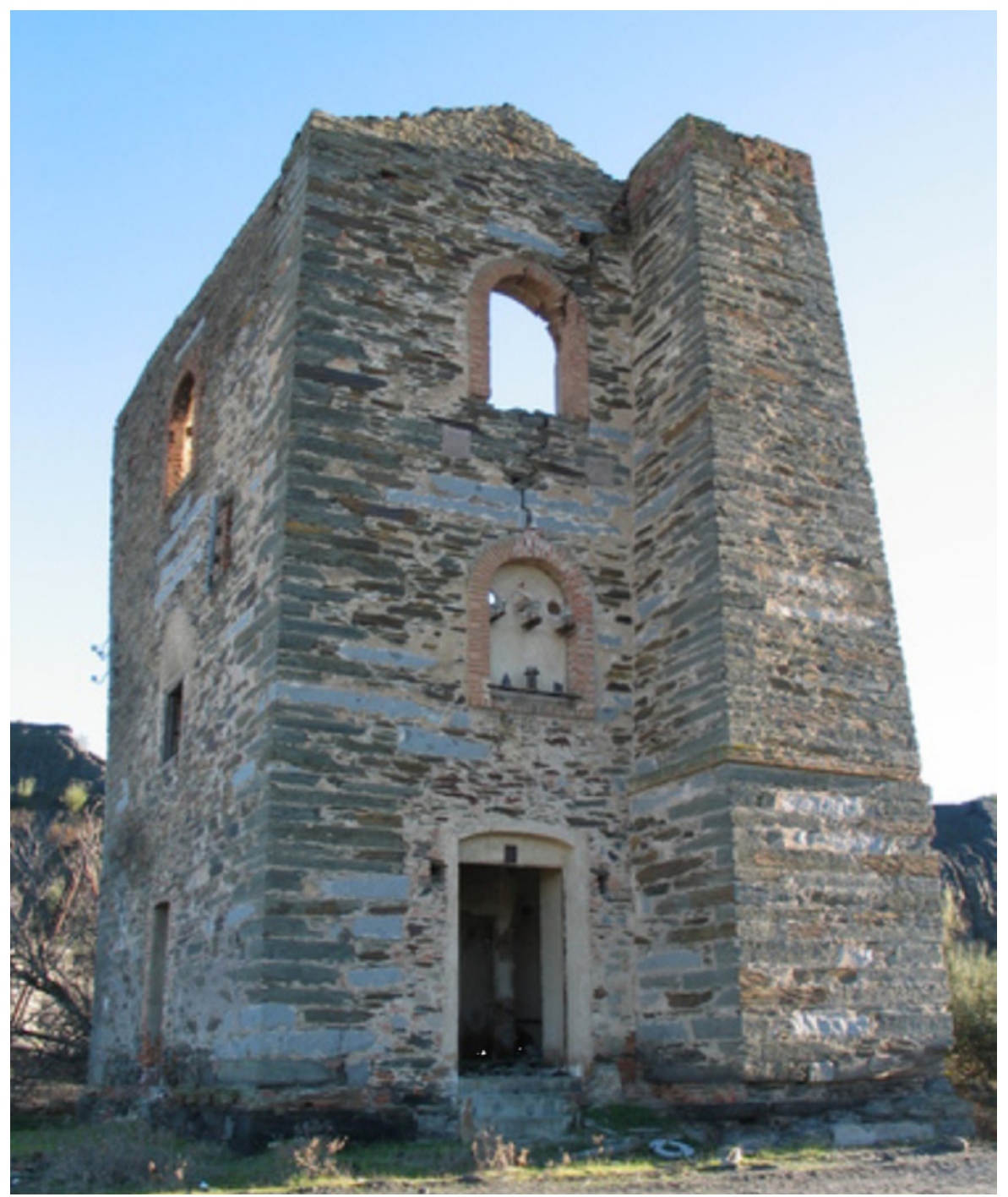

Casa de Máquinas de Mina Terreras

territorio estuvo inexorablemente unida a la explotación metalúrgica y subsiguiente comercialización con Córdoba y el Mediterráneo: a través del puerto fluvial de la colonia patricia Corduba se canalizaban los minerales de los Pedroches, e inversamente se introducían las innovaciones metalúrgicas, de cerámica, culturales, etcétera. Los vestigios arqueológicos (monedas, ornamentación de metalistería, vidrio...) acreditan no solamente la romanización y etapas subsiguientes, sino el puente que representan los Pedroches entre la meseta y el Mediterráneo, y el Atlántico a través del Guadalquivir (navegable).

Las minas del Soldado y las Morras de Villanueva del Duque y Alcaracejos constituyen un ejemplo antológico del patrimonio industrial y minero de la 


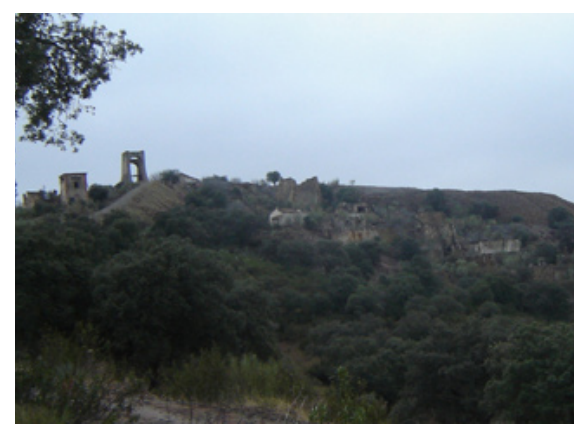

Escombreras de las Morras del Cuzna (Villanueva del Duque, Córdoba)

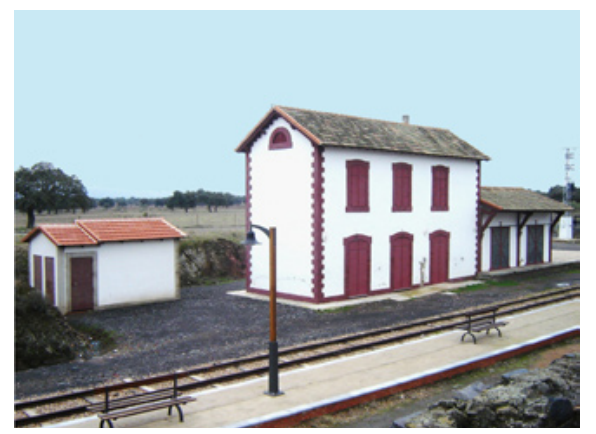

Estación de ferrocarril restaurada del Cerco (Villanueva del Duque)
Antigüedad (cobre, plomo argentífero), revitalizadas a finales del s. XIX y principios del s. XX por la Compañía Minero Metalúrgica de PueblonuevoPeñarroya, de prosapia francesa (LÓPEZ-MORELL, 2005). Las explotaciones subsiguientes, como la islámica de Al-Andalus, son herederas del emporio romano, revitalizadas con nuevos horizontes políticos; y aún en la Modernidad se intentan aprovechar los viejos recursos de siempre, como ocurre en los tiempos de señorialización (s. XVI) de Don Francisco de Zúñiga (MOLINERO, 2012), que a la sazón les dejó para su onomástica la titularidad del duque. Hoy día prevalecen los restos arqueológicos de la actividad industrial de etapa contemporánea (principios del s. XX) sobre las viejas arqueologías.

En el denominado Cerco del Soldado se puede revivir el pasado minero con las estructuras materiales (barrio Tripas con sus cuartelillos, la Subestación, el Cerco) y elementos de la actividad metalúrgica (castilletes, lavadero, casas de máquinas y bombeo, escombreras...): resulta de interés la escombrera del fino, el pozo Luisa y Pepita Norte (con más de 400 m, castillete), casa de máquinas, los vestigios de la capilla, pistas de tenis, paseos y fuentes.... En las Morras del Cuzna y entorno aparecen galerías romanas: los pozos de Carmen y Guadalupe, la casa de Máquinas de Terrera; el conjunto de la mina reservada de Pozogoitia, el balancín de pozo Aguirre y el lavadero (VALVERDE, 2000). Especial interés representa la vía estrecha de ferrocarril, cuyos retazos nos transportan en el tiempo. El Ayuntamiento de Villanueva del Duque ha restaurado con buen tino la casa de Estación para recrear el ferrocarril de la compañía (SMMP), que también cumplió un papel social importante para la población pedrocheña. Hoy día constituye un magnífico corredor como vía verde, perfectamente integrado en el entorno natural.

Con el legado del Cerco del Soldado y las Morras del Cuzna Villanueva mantiene aún muy vivo el pasado de las minas, un legado fundamental, no solamente arqueológico, sino espiritual (ROMERO, A.), que debe serlo para los Pedroches y Andalucía. Actualmente, dicho patrimonio minero e industrial se aprovecha de forma integral con la interpretación del espacio y el paisaje de la dehesa: la comprensión globalizadora del entorno (natural y minero), restauración hidrológica-forestal, dotación de servicios (albergue...), etcétera. En definitiva, nos encontramos ante un testimonio patrimonial magnífico: un conjunto de elementos naturales y culturales, materiales e inmateriales heredados del pasado donde un grupo de personas reconoce una parte importante de su identidad. Toda Andalucía debe de tomar conciencia de que la comarca de los Pedroches, vinculada actualmente a actividades primarias y su transformación, antaño tuvo un importante pasado metalúrgico. 


\section{BIBLIOGRAFÍA}

- CABANAS PAREJA, R. (1968) El macizo batolítico de Los Pedroches. Madrid: Real Academia de Ciencias Exactas, Físicas y Naturales, 1968

- CORZO, R.; JIMENEZ, A. (1980) Organización territorial de la Baetica. Revista AEspA, 53, 1980, pp. 21-48

- HERNANDO LUNA, R. (1989) Aportaciones de la minería cordobesa. Explotaciones de cobre, plomo, cinc (1850-1929). 1989, tesis doctoral (inédita)

- HERNANDO LUNA, R. (1982) La Sociedad Minera Metalúrgica de Peñarroya. Una empresa centenaria. Notas sobre sus orígenes y primeras etapas de actividad. Revista de Feria de Peñarroya-Pueblonuevo, 1982

- GARCía ROMERO, J. (2002) El papel de la minería y la metalurgia en la Córdoba romana. Córdoba: Servicio de Publicaciones, Universidad de Córdoba, 2002

- JIMÉNEZ SAN PEDRO, R. (2005) El complejo filoniano tardihercínico asociado al batolito de Los Pedroches. Bilbao: Universidad del País Vasco, 2005

- MÁRQUEZ TRIGUERO, E. (1966) Contribución al estudio metalogenético de Los Pedroches. Córdoba: IGME, 1966

- MERINO MADRID, A. (2000) Córdoba y sus pueblos en las fuentes latinas. Revista Cuzna. Revista de Investigación y Didáctica, n. ${ }^{\circ} 3$, Córdoba, 2000, pp. 115-127

- MOLINERO MERCHÁN, J. A. (2012) Villanueva del Duque. Lucha histórica por la libertad. Córdoba: Diputación Provincial de Córdoba-Ayto. Villanueva del Duque, 2012

- MURILlO, J. (1987) Poblamiento protohistórico y minería en el norte de la provincia de Córdoba. En Actas del I Coloquio de Historia Antigua de Andalucía. Córdoba: Publicaciones del Monte de Piedad y Caja de Ahorros de Córdoba, 1987

- ROMERo, M. ${ }^{a}$ A. (2010) Influencia de la minería en la sociedad villaduqueña. Boletín de la Feria de Villanueva del Duque, 2010

- STYLOW, A. V. (1985) Ordenación territorial romana en el valle de Los Pedroches (conventus cordubensis). En XVII Congreso Nacional de Arqueología, 14-16 septiembre, 1983. Zaragoza: Secretaría General de los Congresos Arqueológicos Nacionales, Universidad de Zaragoza, 1985, pp. $157-666$

- VALLE BUENESTADO, B. (1985) Geografía agraria de Los Pedroches. Córdoba: Diputación Provincial, Servicio de Publicaciones, 1985

- VAlVerde ROMERo, J. C. (2000) Estudio histórico geominero del Valle de Los Pedroches. En Informe para LEADER, 2000 (en prensa)
- LÓPEZ-MORELL, M. A. (2014) La Sociedad Minero Metalúrgica de Peñarroya: historia de una gran empresa minera. Ponencia en las IV jornadas de historia de Villanueva del Duque (25 y 26 de abril), 2014 (inédito)

- LóPEZ-MORELL, M. A. (2005) La Casa Rothschild en España (1812-1941). Madrid: Marcial Pons Historia, 2005 